\title{
Australian Capital Gains and Commodity Taxes in China: Impact on Investor Behavior and Revenue Earnings
}

\author{
Debasis Patnaik, Madhulekha \\ Birla Institute of Technology and Science, Goa, India
}

\begin{abstract}
Apart from examining whether an asset's qualification for discounted tax treatment is associated with positive abnormal trading volumes and negative abnormal returns, as would be predicted if investors modified their behaviour to reduce their tax liability, this paper analyses the behaviour of investors due to market sentiment which is measured with the stock prices or index. Analyzing the 152 IPOs that had their prices appreciated, the Capital Gains Tax (CGT) concession is expected to change the behavior of the investor; they might wait till the end of 12 months in order to avail the option and then sell their asset leading to an abnormal increase in the volume of trading and hence a price change. Apart from this, how commodity taxes influence revenue earnings is studied. As the Gross Domestic Product (GDP) of China grows rapidly, tax revenue as a proportion of GDP will not be a predictable relationship. It is ultimately investor behaviour that determined volume of investment and therefore revenue earnings. The reason that CGT is taken as a backdrop to show the fickle nature of $\mathrm{K}$ gains across national policy sets up, affected by investor behavior or otherwise.
\end{abstract}

Keywords: capital gains tax (CGT), commodity tax, abnormal trading volumes, expected returns, regression, investor behavior

\section{Introduction}

CGT is the amount you have to pay to the government for every capital gain that one gets when selling off an asset; the realized capital gain is taxed. This tax may be expected to influence investor's behavior. A reduction in CGT for individuals on realized capital gains resulted in an increased volume of share transactions on the New York stock exchange, American stock exchange, and in the over-the-counter market. A unique opportunity has arisen in the Australian context to examine this issue. Since the introduction of CGT reforms is in September 1999, Australian investors have been able to claim a 50\% discount on the CGT payable on assets that have been held for a period of 12 months or more. The aim of this paper is to test whether the passing of the 12-month qualification date has an impact on individual investor's trading behavior.

This can be measured by the sudden increase in the trading volume after the 12 months is over, which creates a price pressure in the market and the price falls. Now this can act as the indicator to find out whether

Debasis Patnaik, Ph.D., Head of Department of Economics, Birla Institute of Technology and Science, Pilani, K. K. Birla Goa Campus, Goa, India.

Madhulekha, M.Sc. Economics and B-tech Computer Science, Birla Institute of Technology and Science, Pilani, K. K. Birla Goa Campus, Goa, India.

Correspondence concerning this article should be addressed to Dr Debasis Patnaik, Department of Economics, BITS, pilani, K. K. Birla Goa campus, 17B Bypass Road, Zuari Nagar, Vasco, Goa, 403726, India. E-mail: marikesh@goa.bits-pilani.ac.in; marrikesh@yahoo.com. 
volume of trading actually changes. The issue of abnormal trading volumes was taken care of by testing whether the average weekly turnover rate in the week of qualification was higher than the average weekly turnover rate in the preceding weeks. A problem with this approach arises as a result of the aggregation of a very disperse set of weekly turnover rates experienced in the relatively illiquid Australian market. Instead, this paper standardizes weekly trading volumes for each security during the five-week testing period by reference to the average weekly trading volume experienced by the security during a specified control period.

A regression analysis has used many independent variables, which include:

- $C G_{i}$, as the difference between the price of security " $i$ " 16 days prior to the 12 month anniversary of listing and its subscription price, divided by its subscription price; $V_{i}$ is the total dollar value of shares traded in security " $i$ " in the week in which the abnormal trading volume is measured;

- $D_{-1}, D_{0}, D_{+1}$ and $D_{+2}$ are dummy variables that take on a value of 1 where the observation takes place in weeks $-1,0,+1$ and +2 respectively and a value of 0 otherwise. The stock index value has also been included to this regression analysis as it could be an important factor that will lead the investor to sell his asset. This in turn would lead to an increase in the trading volume.

Taxes provide the most important revenue source for the Government of the People's Republic of China. As the most important source of fiscal revenue, tax is a key economic player of macroeconomic regulation and greatly affects China's economic and social development. With the changes made since the 1994 tax reform, China has preliminarily set up a streamlined tax system geared to the socialist market economy.

China's economic transformation during the past 20 years has been breath-taking. As the early 1980s, China was one of the poorest countries in the world. The economy was almost entirely state-owned. Virtually all allocation decisions were made through the government planning ministries. Goods were largely rationed, prices were only an accounting convention, and the economy was largely closed. Since then, per capita GDP has grown by a factor of at least five. The country has largely shifted to a market economy, most industries are highly competitive, and international trade with the rest of the world is large and the number is growing. There is now a vibrant private sector, rapid foreign direct investment, and a thriving stock market. While the state-owned sector still constitutes 53\% of industrial value-added and 15\% of gross industrial output (March 2002), these fractions continue to drop steadily.

What explains this dramatic success of the Chinese economic reforms to date? Many answers can be and have been explored. The main source of tax revenue for the national government was taxes (and dividends) collected from large capital-intensive firms, which were almost entirely owned by the national government. Statutory profits tax rates were very high and there were many supplementary taxes and fees in addition. Two other important sources of revenue were high tariffs on imports and high seigniors due to a rapid growth in the money supply. In spite of the high tax rates, revenue collection was not that high, partly because only a small part of the economy was subject to these taxes.

In addition, the rate of evasion on these taxes was high and due to high rates of corruption many payments never showed up in reported government revenue.

Hanlon and Pinder (2007) tested whether investor behaviour is affected by CGT reforms. Specifically, the paper considered whether the application of a discounted tax rate to assets held for 12 months or more is sufficient to induce individual IPO subscribers to sell their holdings in the immediate post-qualification period. The New Business Tax System (Capital Gains Tax) Act 1999 (Cth) significantly changed the treatment of 
capital gains in Australia. From September 21, 1999, an individual investor who holds an asset for 12 months or more is now subject to CGT on half the nominal capital gain at their marginal tax rate. The paper reported evidence of statistically significant abnormal trading volumes for shares that experienced high positive capital gains during the trading week beginning on the 12-month anniversary of listing. Whilst there is only limited evidence that this abnormal trading volume is associated with statistically significant negative returns during the qualification week, this is not unexpected given the relatively small proportion of remaining individual shareholders that the reforms apply to and the probable anticipation by the market of such shareholder behaviour.

\section{Objectives}

The objective of this paper is to find out whether the stock price value influences the trading volume which in turn decreases the price. The CGT concession which is valid when you hold an asset for over 12 months might or might not influence the investor behaviour. This paper seeks to find out whether the null hypothesis, i.e. all the parameters being 0 , can be rejected or not.

Apart from this, the effect of the commodity tax rates in China which was implemented in 2005 is also studied.

\section{Methodology}

Apart from the independent variables, the abnormal trading volume might also depend on the stock index value which will guide an investor to sell or hold an asset.

Tax revenue change is taken as a percentage of GDP and the tax rate is the percentage of price of commodity. Regression analysis gives beta coefficients which are the determinants of how they are related.

The central premise to be tested in this paper is that investors will delay realisation of a capital gain until it qualifies for discounted tax treatment. This problem is approached by testing for any evidence of abnormal trading volumes and/or price pressure effects.

Therefore, the hypothesis to be tested, with respect to the sample of appreciated shares, is that Abnormal Trading Volume (ATV) is higher following qualification for discounted CGT status than that in the weeks prior to qualification.

The degree of abnormal trading volume observed will be a function of the incentive to undertake tax-minimisation behavior, which in turn is directly related to the magnitude of the capital gain itself. To address this issue, the following regression was estimated:

$$
\mathrm{ATV}_{\mathrm{i}}=\alpha_{0}+\alpha_{1} C G_{i}+\alpha_{2} V+\Sigma \beta_{k} D_{k, i}+\Sigma \gamma_{k} D_{k, i} . C G_{i}+\epsilon_{i}
$$

where $C G_{i}$ is as the difference between the price of security " $i$ " 16 days prior to the 12 month anniversary of listing and its subscription price; $V_{i}$ is the total dollar value of shares traded in security " $i$ " in the week in which the abnormal trading volume is measured; $D_{-1}, D_{0}, D_{+1}$, and $D_{+2}$ are dummy variables that take on a value of 1 where the observation takes place in weeks $-1,0,+1$ and +2 respectively and a value of 0 otherwise.

If there is evidence of positive abnormal trading volumes in the period following qualification and the marginal investor is an individual IPO subscriber realising their capital gain, then it is recording a negative price impact as a result of this selling pressure. To test this, weekly market-adjusted returns (MAR) were calculated over the test period using the all ordinaries accumulation index as a proxy for expected returns. 


$$
A T V_{i}=\alpha_{0}+\alpha_{1} C G_{i}+\alpha_{2} V+\Sigma \beta_{k} D_{k, i}+\Sigma \gamma_{k} D_{k, i} . C G_{i}+\alpha_{3} P+\epsilon_{i}
$$

Where $P$ is the price of the stock price of the Australian stocks which was available for the five weeks when the study was conducted (Table 1).

Table 1

Weekly Distribution of Abnormal Trading Volume

\begin{tabular}{lc}
\hline Week (selling time) & ATV \\
\hline-2 & -0.065 \\
-1 & -0.247 \\
0 & 0.426 \\
1 & -0.357 \\
2 & -0.483 \\
\hline
\end{tabular}

The price will affect the investor's behavior towards selling off the share or to retain it for longer time for profits. The prediction about the market and the sentiment of the investor of whether the market is bearish or bullish and whether he will go with the stock prices determine his abnormal returns.

The regression results gave coefficients which are discussed in the results.

The fact that the coefficients were insignificant means that the stock prices did not change the behaviour of the investors. The abnormal returns did not change because of any stock price movements.

\section{An Analysis of Revenue From the Commodity Taxes in China}

From the data below (Table 2, 3, and 4), it can be seen that tax revenue in absolute terms is increasing over the years but tax as a percentage of GDP has fallen. Tax by itself hasn't contributed more over the years hence the decrease.

The given Table 2 shows only a few years but the same trend was observed from the entire data. The percentage tax revenue of GDP has fallen over the years which were regressed by the tax rate imposed. Negative beta coefficients are observed.

Table 2

Tax Revenue in Yuan and \% of GDP

\begin{tabular}{lcl}
\hline Year & Tax revenue in Yuan & Tax revenue as a \% of GDP \\
\hline 1990 & 96.1 & 15.2 \\
1991 & 299.02 & 13.8 \\
1992 & 329.69 & 12.4 \\
1993 & 425.53 & 12.3 \\
1994 & 512.69 & 11.0 \\
1995 & 603.80 & 10.3 \\
1996 & 690.98 & 10.2 \\
1997 & 823.40 & 11.0 \\
\hline
\end{tabular}

A regression analysis (Table 3) was done with the following data

$$
Y_{i}=\beta_{0}+\beta_{1} X_{1}+\beta_{2} X_{2}+\beta_{3} X_{3}
$$

Where $Y i$ is the tax revenue collected as a percentage of GDP;

$X_{1}, X_{2}$, and $X_{3}$ are the commercial tax, income tax, and the corporate tax. 
Table 3

\begin{tabular}{lllll}
\multicolumn{2}{l}{ Regressed Data } \\
\hline Year & Tax revenue (\% of GDP) & Tax rate (\% of commercial profits) & Income tax & Corporate tax \\
\hline 2003 & 8.538996219 & 80 & 45 & 33 \\
2004 & 8.860551515 & 80 & 45 & 33 \\
2005 & 8.679594442 & 80 & 45 & 33 \\
2006 & 9.188060347 & 80.7 & 45 & 33 \\
2007 & 9.928816567 & 81.2 & 45 & 33 \\
2008 & 10.26866091 & 79.9 & 45 & 25 \\
2009 & 10.53972933 & 63.8 & 45 & 25 \\
2010 & 10.48181247 & 63.5 & 45 & 25 \\
2011 & 12.5 & 63.5 & 45 & 25 \\
2012 & 11.2 & 63.7 & 45 & 25 \\
\hline
\end{tabular}

Table 4

OLS (Using Observations 1-10)

\begin{tabular}{lclcc}
\hline & Coefficients & Standard error & $t$-ratio & $p$-value \\
\hline Constant & 3.11606 & 0.190624 & 16.3466 & 0.00001 \\
Tax on commodity & -0.00451994 & 0.00228944 & -1.9743 & 0.08893 \\
Corporate tax & -0.0167466 & 0.00293887 & -5.6983 & 0.00074 \\
Mean dependent variable & 2.297611 & S.D. of dependent variable & 0.122441 & \\
Sum squared residual & 0.035516 & S.E. of regression & 0.071230 & \\
$R^{2}$ & 0.736775 & Adjusted $R^{2}$ & 0.661568 & 0.001501 \\
$F(2,7)$ & 18.92924 & $p$-value $(F)$ & -22.02486 & \\
Log likelihood & 14.01243 & Akaike criterion & -23.0206 & \\
Schwartz criterion & -21.11711 & Hannan quinn &
\end{tabular}

Note. Dependent variable: tax revenue; Heteroskedasticity-robust standard errors.

\section{Summary}

The passing of the discount qualification date is only expected to be significant to the determination of abnormal trading volumes for IPOs that have experienced a capital gain in the post-listing period.

As the CGT consequences of incurring a capital loss are not affected by the length of time an asset has been held, there is no tax benefit in deferring realization of the capital loss associated with IPOs that have depreciated in value until passing the 12 month anniversary of listing. Therefore, the fact that the coefficients for the variables relating to the passing of the 12 month anniversary of listing $\left(\beta_{0}\right.$ and $\left.\gamma_{0}\right)$ were not significant is to be expected.

An insignificant $\beta_{0}$ implies that the passing of the qualification date is not enough to impact trading volumes. The finding that $\gamma_{0}$ is significant in the regression relating to the appreciated sub-sample indicates that abnormal trading volumes are significantly higher during the qualification week for firms that have appreciated by higher amounts.

The result indicates that investors will choose an optimal tax strategy over an optimal risk strategy when the tax penalty for risk minimization is greatest.

The stock price addition also did not lead to a significant $\beta$ value. The fact that the target investors are still a narrow spectrum of all the investors in Australia continues to be the reason why CGT might still not be a strong factor for investors' behavioral changes and their hold on to the assets. 
Findings from China's Commodity tax rate are:

- From the regression, it is found out the beta values are negative;

- The tax rate has decreased over the years, which is the reason why our beta coefficients are negative;

- This relationship is negative because the decrease in tax rate did not decrease the tax revenue, maybe because the volume of trade increased. More traders entered the market and the supply itself increased, which would lead to the increase in the tax revenue;

- Similar reasoning would be applicable to the other taxes too. The corporate tax decreased too but the revenue tax as a percentage of GDP did not decrease. Income tax was a constant hence there was no coefficient.

\section{Conclusions}

An individual investor will seek to minimize their CGT liability when the non-tax costs of doing so are outweighed by the tax benefits to be derived. The investors with the most wealth invested in stocks consistently traded to minimize their CGT liability. The importance of long-term and short-term CGT distinctions is lessened if investors have lower income and wealth. This is consistent with the idea that dynamic tax-minimization strategies, such as postponing realization of short-term capital gains until they become long-term, are cost-effective only for those taxpayers with high levels of wealth at stake.

The results supporting the presence of positive abnormal trading volume coupled with the absence of any strong evidence of a price effect around the 12-month anniversary of listing may be consistent with the market having already incorporated the expectation of the selling pressure by individual shareholders into prices before the 12-month anniversary.

The stock index value did not change the conclusion that beta values still continue to be insignificant. The effect on public finance is that the government is not losing out on the tax revenue that it gets from the investors who sell assets in a short duration.

Since 1998, the China's tax revenue has been increasing annually and it has played an important role in the improvement of the government macroeconomic control and the national economic situation. However, the long term abnormal increase of tax revenue has aggravated the burden of enterprises and residents, depressed the domestic investment and consumption, and also hurt the international competition capability of enterprises. Under the current domestic and international situation, China, for the purpose of benefiting sustainable development of the national economy, should perfect its tax systems and implement the policy of moderate tax reduction. The recent years has shown a tax rate cut in commercial profits which hasn't decreased the revenue from taxes.

\section{References}

Bayley, L., Lee, P., \& Walter, T. (2003). IPO flipping in Australia: Cross sectional explanations (Working Paper 2003-03, School of Banking and Finance, University of New South Wales).

Blouin, J. L., Raedy, J., \& Shackelford, D. A. (2002). Equity price pressure from the 1998 reduction in the capital gains holding period. Journal of the American Taxation Association, 24, 70-93.

Blouin, J. L., Raedy, J., \& Shackelford, D. A. (2003). Capital gains taxes and equity trading. Journal of Accounting Research, 41, 611-650.

Brown, S. J., \& Warner, J. B. (1985). Using daily stock returns: The case of event studies. Journal of Financial Economics, 14, 3-31.

Chaplinsky, S., \& Seyhun, H. N. (1990). Dividends and taxes: Evidence on tax-reduction strategies. Journal of Business, 63, 239-260. 
Constantinides, G. (1984). Optimal stock trading with personal taxes: Implications for prices and the abnormal January returns. Journal of Financial Economics, 13, 65-89.

Dyl, E. (1977). Capital gains taxation and year-end stock market behavior. Journal of Finance, 32, 165-175.

Hanlon, D., \& Pinder, S. (2007). An empirical investigation of whether Australian capital gains tax reforms influence individual investor behavior. Pacific-Basin Finance Journal, 15, 481-493 